\title{
Oxygen Uptake During Exoskeletal-assisted Walking in Persons with Paraplegia
}

Steven Knezevic, Racine R. Emmons, Pierre K. Asselin, Ann M. Spungen

William Paterson University, Wayne, NJ, James J. Peters VA Medical Center, Bronx, NY

PURPOSE: Paraplegia often leads to being confined to a wheelchair, resulting in a sedentary lifestyle and secondary medical complications from paralysis. It is important to determine interventions which promote physical activity within this population. The purpose of this study was to quantify oxygen uptake $\left(\mathrm{VO}_{2}\right)$ during exoskeleton-assisted walking (EAW) and to determine if was related to EAW velocity in persons with paraplegia. METHODS: Five male participants with paraplegia (PARA) and five ablebodied $(\mathrm{AB})$ subjects matched for height $( \pm 12.7 \mathrm{~cm})$ weight $( \pm 6.8 \mathrm{~kg})$ and age $( \pm 5$ years $)$ were recruited to serve as a control group. A portable metabolic cart (OxyconMobile, Carefusion, San Diego, CA) was used to obtain the measurements of the exhaled gases for the calculation of $\mathrm{VO}_{2}$. $\mathrm{VO}_{2}$ efficiency (VOE $\mathrm{ml} / \mathrm{kg} / \mathrm{m}$ ) was calculated using the average $\mathrm{VO}_{2}(\mathrm{ml} / \mathrm{kg} / \mathrm{min})$ during the 6 -minute walk test (6MWT) divided by the distance traveled $(\mathrm{m}) . \mathrm{VO}_{2}$ measurements were obtained during the 6MWT for both groups, for PARA during EAW and the $\mathrm{AB}$ group during walking on their own at two fixed velocities $(<0.25 \mathrm{~m} / \mathrm{s}$ and $>0.40 \mathrm{~m} / \mathrm{s})$. Rating of perceived exertion (RPE) was measured at all sessions using the Borg Scale. Unpaired t-tests were used for the group demographic comparisons. Percent change variables were calculated in PARA from pre to post, and in AB between the two velocities, and analyzed by a paired samples t-test. RESULTS: The five male PARA were between 37-61 years old, 22.7-28.6 $\mathrm{kg} / \mathrm{m}^{2} \mathrm{BMI}$, ranged from T1-T11, and were 1.5-14 years since injury. There were no significant differences between the groups for the demographic variables. In PARA, EAW velocity significantly improved from pre to post $(0.14 \pm 0.14 \mathrm{~m} / \mathrm{s}$ vs. $0.28 \pm 0.12, \mathrm{P}=0.023)$ and VOE significantly improved by $50 \pm 32 \%$ (CI: 10 to $90, \mathrm{P}=0.025$ ); this change in VOE was consistent with reporting of lower RPE scores. In $A B, V O E$ at the faster velocity was $61 \pm 4 \%$ (CI: 56 to $65, \mathrm{P}<0.0001)$ more efficient than the slower velocity. CONCLUSION: The current study suggests that ambulating at faster speeds is more efficient than slower speeds in PARA EAW and AB regular walking. As proficiency and velocity in EAW improves with training, the idea of independent walking within the SCI population is beginning to make its way into reality.

Supported by VA Rehabilitation R\&D Service (\#B9212-C) 